\title{
AN ALTERNATIVE APPROACH TO ASSESS THE RESIDENTIAL POPULATION RESILIENCE TO URBAN FLOODING
}

\author{
KALPANA. L.D.C.H.N. ${ }^{1}$, JAYASINGHE. A.B. ${ }^{2}$, ABENAYAKE. C.C 3 \& WIJAYAWARDANA. P.N.P.4 \\ 1, 2,3,4Department of Town and Country Planning, Faculty of Architecture, University of Moratuwa, Sri Lanka. \\ hnhasinthanawod@gmail.com¹,amilab@uom.lk², chethika@uom.lk³,naduniwi@gmail.com4
}

\begin{abstract}
Community resilience assessments and minimizing the anticipated disruptions to vulnerable communities, is a broad topic in disaster studies. In common practice, most of the indicator-based resilience assessment studies rely on statistical aggregation methods of tabular data collected for macro administrative units, as it is readily available in most of the countries. However, this method confronts severe drawbacks in converting such data into micro-scale geospatial units. To address those issues, this study proposes to utilize the Dasymetric Mapping Technique in the geospatial population resilience assessments, as it is capable of identifying the micro level impact to the population distribution as a pixel representation. In order to geospatially demonstrate the population exposure, the study has selected three major flooding events occurred in Colombo, Sri Lanka. The results revealed a great applicability of the proposed method as a statistical approach which estimates the exposed population by over 90\% accuracy. Therefore, the proposed method is recommended to be utilized as an efficient tool of community resilience assessment as it is highly accurate in downscaling the spatial distribution of population data.
\end{abstract}

Keywords: Community Resilience Assessment, Disaster Management, Dasymetric Mapping Technique, Urban Flooding

\section{Introduction}

Flooding is considered a global threat, as it disrupts the livelihood in many dimensions and makes a significant impact on the people, the economy and the environment. It is estimated that $47 \%$ of flood and storm-related events have affected 2.3 billion people in the world during the last decade (1995 - 2015); (Wahlstrom \& Guha-Sapir, 2015). In 2010 alone, 178 million people were affected and the total economic loss exceeded USD 40 billion. (WMO, 2015). Extreme rainfall events or uncertainties, an agglomeration of population, unplanned urban development, increasing imperviousness and poorly maintained drainage systems lead to frequent flooding, causing damage to the population and these conditions triggers their vulnerability at a higher rate. (Singh, et al., 2018); (Pregnolato , et al., 2016); (Jha, et al., 2012); (Dover, 2015). Therefore, resilience building has become an important way for city planners and decision makers to manage flood risks (Abenayake, et al., 2016). Many global agendas such as Sendai Framework for Disaster Risk Reduction 2015-2030, the Sustainable Development Goals (SDG) for 2030, and the World Humanitarian Summit Commitments to Action and the New Urban Agenda emphasize the importance of such measures (UN-Habitat, 2017).

In the ecological domain, the term 'resilience' is defined as "the measure of the persistence of systems and their ability to absorb change and disturbance, yet maintain the same relationships between populations or state variables" (Holling, 1973). Thus, nowadays it is commonly used in many disciplines and in resilience building studies, and is mainly considered the functionality of the system under a disaster driven situation in order to understand the impact on the vulnerable communities (Serre, 2018). Hence, this insight will elaborate the understanding of practitioners to improve the degree of susceptibility (Hammond, et al., 2015). Thus, the corresponding studies examines the community resilience to urban flooding and the applicability of the methodology to assess population resilience to urban flooding.

Considering the Sri Lankan situation, floods are identified as the most frequent natural disaster, where thousands of people island-wide are affected every year. According to the DMC and UNOCHA records, the 15th of May 2016 flooding event affected 301,602 people in the whole country causing more than 104 deaths; and 99 people were reported missing (UNOCHA, 2016). Floods in 2017 may have caused distress to 879,778 of the population where 219 deaths and 74 missing persons were reported (DMC, et al., 2017); (UNOCHA, 2016). These statistics also highlight the increasing flood vulnerability of urban areas. The predominant causes of flooding are identified as the rapid growth of population and unplanned urban development activities which have disrupted the natural flow of rain water circulation and topography. These flooding events are defined as urban flooding (Papagiannaki, et al., 2017); (Yin, et al., 2016); and this particular study 
focuses on assessing the population resilience for flooding urban areas, as those areas account for the higher portion of active labor force and economic contribution to the GDP and hence, extremely important to the socioeconomic development of the country.

Although ample geospatial studies have been conducted to discuss the quantitative analytical methods of measuring the infrastructure resilience of urban flooding, there have been very limited quantitative studies to assess community resilience (Abenayake, et al., 2018). This is mainly due to the contemporary analytical methodologies, complexity of the population distribution and the nature of demographic data representation in spatial platforms (Jayasinghe \& Munasinghe, 2012); (Jayasinghe, et al., 2020). As shown in the Figure 1, the population data is generally represented by a choropleth map, where the statistical data is aggregated to areal units (i.e. GN Divisions), and which does not represent the actual population distribution due to the topology and landuse differentiations (Mennis, 2003); (KALPANA, et al., 2019). Hence, such measures do not adequately capture the real significance of population resilience, although several literatures have utilized them in different ways to focus on the recovery phase of the flood events to measure the population resilience (Wenjuan, et al., 2020). In order to address that gap, this research proposed an alternative approach to measure the population resilience, based on the dasymetric mapping technique (Mileua \& Queirósa , 2018). The core area of Colombo was taken as the study area and recent flooding events were selected to measure the flood exposure of population.

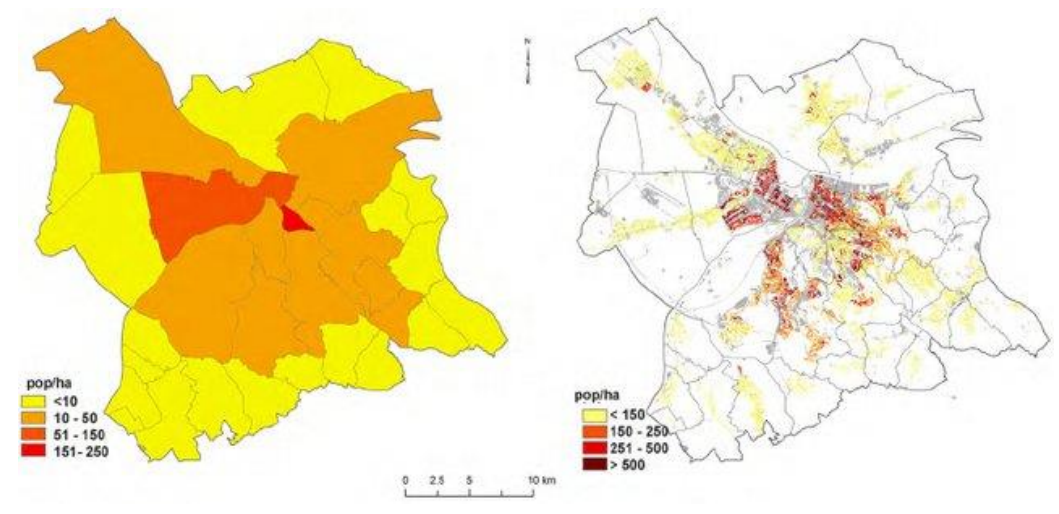

Figure 1: Population shown in Choropleth map (left) and dasymetric map (right), (Bajat, et al., 2013)

The remainder of the paper is organized as follows: The application of the dasymetric mapping method is briefly discussed in Section 2. Methodology and data description is introduced in Section 3. Analytical results and a brief discussion on findings are presented in Section 4. Finally, the summary and an outline of future research directions are provided in Section 5.

\section{Dasymetric mapping method.}

The dasymetric mapping technique is identified as a population downscaling technique which follows the areal interpolation method (WU, et al., 2005). It basically transfers the spatial data from one spatial zone to another based on the ancillary information, which is usually extracted from the satellite imagery classifications and landuse data registries (Nicolau, et al., 2019). Although there have been several dasymetric mapping approaches based on a variety of ancillary information, this study follows the dasymetric mapping approach proposed by Nelson and Margarida (Mileua \& Queirósa , 2018)along with several model enhancements. The proposed dasymetric model was developed based on the Python Language, but the model did not respond well due to internal corruptions. Therefore, the model architecture was changed by authors and the same model was built in QGIS Model Builder environment, as it was easier to make improvements and the necessary adjustments. In order to calculate the population of each land cover cell, it follows the modified equation of (Holloway, et al., 1997).

$$
P=\frac{\left(R_{n} A_{n}\right) \times N}{E}
$$


Wherein,
$P \quad$ : Population of a cell
$R_{n} \quad$ : The relative density of the mapping unit population with land-cover type A
$A_{n} \quad$ : The area of mapping unit
$E$ : The expected population of the enumeration unit calculated using relative densities
$N \quad$ : The actual population of the enumeration unit

The study follows the same ancillary classification to prepare the dasymetric map, as it is applicable for the Sri Lankan landuse classification. Thus, it classifies the landuse layer into four ancillary classes as: I. High-Density Residential, II. Low-Density Residential, III. Non-Urban inhabited, IV. Uninhabited and distributed in each GN Division's population, according to the GN Division's ancillary information. The study is based on the Department of Census and Statistics 2012 population census data and National Metadata Catalogue (NDSI) Landuse Data. The detailed steps of preparing the dasymetric map, are presented in the methodology section.

\section{Methods and Materials}

\subsection{DATA DESCRIPTION}

The data used for the particular study is summarized in Table 1.

Table 1: Data Description

\begin{tabular}{|l|l|l|l|}
\hline Data Type & Year & Source & Description \\
\hline Population Data & 2012 & $\begin{array}{l}\text { Department of Census and } \\
\text { Statistics (DCS) }\end{array}$ & GIS Files (Polygon) \\
\hline Landuse Data & 2015 & $\begin{array}{l}\text { National Metadata Catalogue } \\
\text { (NSDI) }\end{array}$ & GIS Files (Polygon) \\
\hline Flood Maps & $2010,2016 \& 2017$ & $\begin{array}{l}\text { Center for Urban Water, Sri Lanka } \\
\text { (CUrW) }\end{array}$ & Image Files (JPEG) \\
\hline
\end{tabular}

\subsection{STUDY FRAMEWORK}

The overall method of study is illustrated in Figure 2.

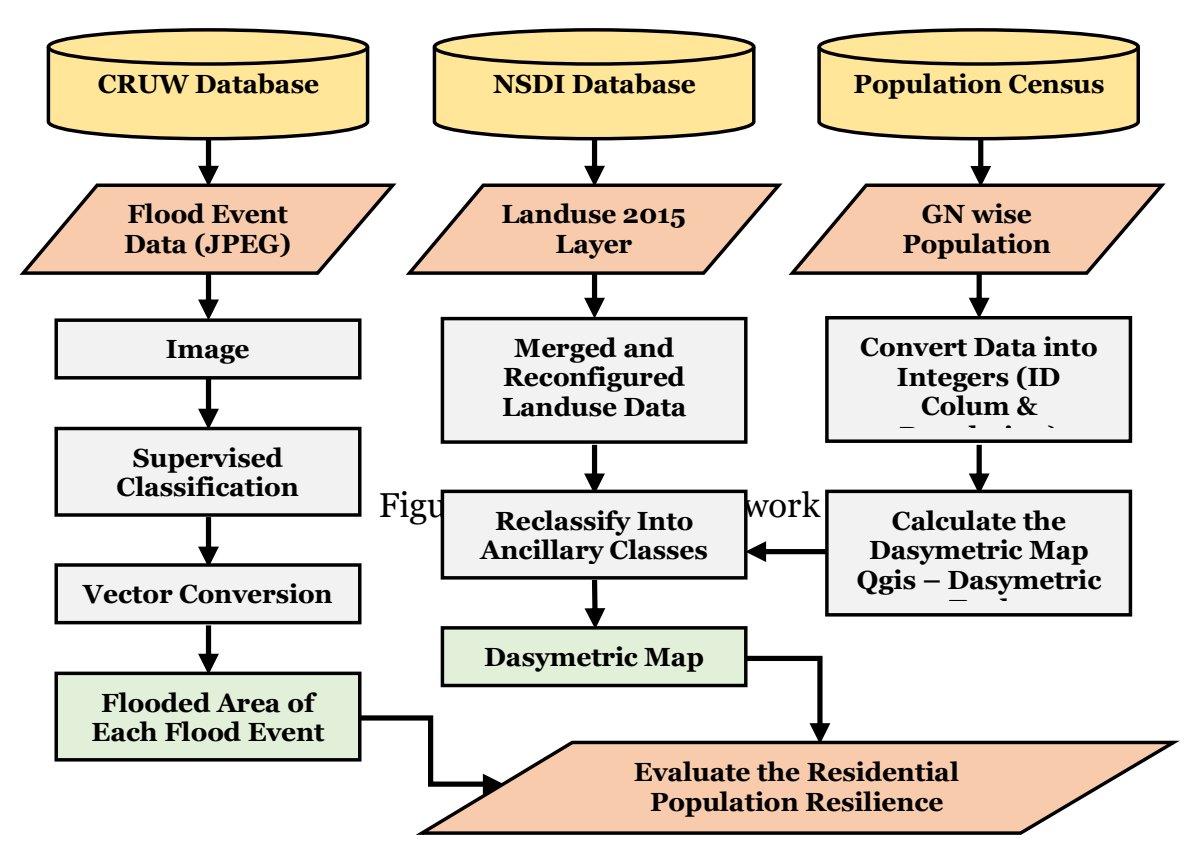

Figure 2: Study Framework 


\subsection{STUDY AREA}

In order to demonstrate the exposed population, the study selected the core area of Colombo for the case study, which is considered a highly urbanized zone in Sri Lanka. Three consecutive urban flooding events were selected as shown in Table 2, along with the significance of each event.

Table 2: Characteristics of Selected Flood Events.

\begin{tabular}{|l|l|l|}
\hline Onset of Flooding & Impacted Area & Affected Population \\
\hline 2010 May 17 Flood & 41 Sq.km & 91,000 \\
\hline 2016 May 15 Flood & 32 Sq.km & 228,871 \\
\hline 2017 May 25 Flood & 22 Sq.km & 21,000 \\
\hline
\end{tabular}

\section{Results And Analysis}

The population dasymetric map prepared under the 250m resolution (250 Cell Size) is shown in Figure 3. The map disaggregates the population according to the ancillary information and uninhabitable areas present zero population.
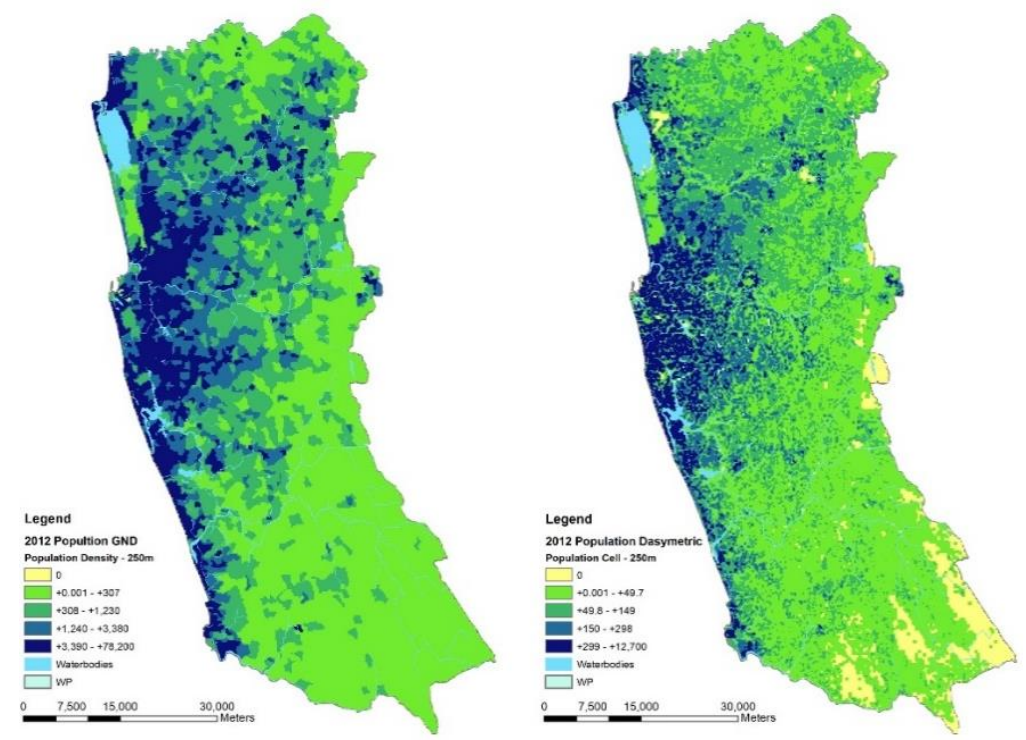

Figure 3: Population Density Distribution According to the GN Divisions (Left Map), Dasymetric Population Distribution (Right Map)

Figure 4 depicts the comparative zoomed-in density diagrams of GN division and Dasymetric mapping overplayed with the administrative boundary.
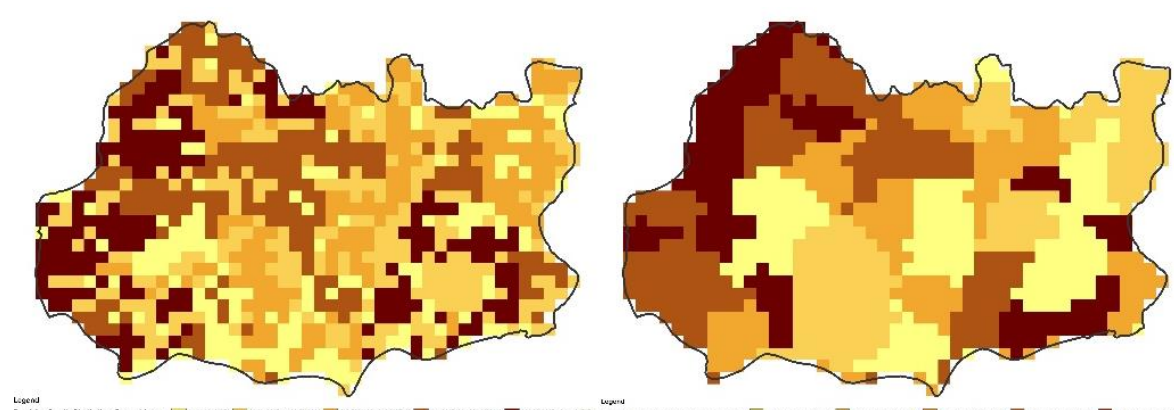

Figure 4: Zoomed View of Population Distribution, GN Division (Right) and Dasymetric Map (Left) (Darker the color, higher the concentration of population) 
In order to evaluate the population distribution obtained from the dasymetric map, the map is compared with the statistical population distribution map. It calculates the sum of each pixel which represent each GND and then the absolute difference of the two variables is calculated by subtracting the GND population. Figure 5 shows the histogram of absolute difference of the two valuables.

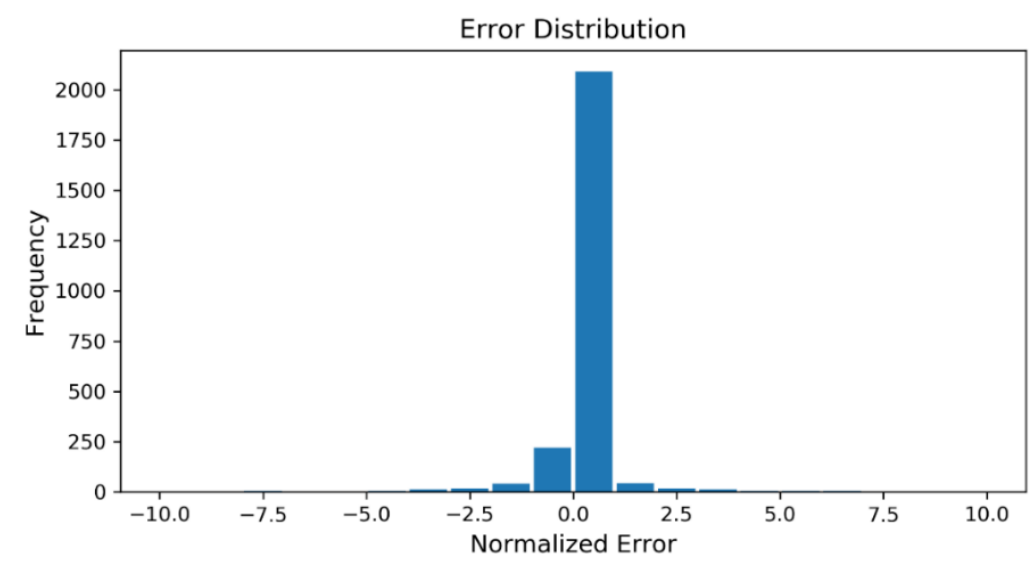

Figure 5: Absolute Difference between the GND and Dasymetric Population Distribution

The Histogram shows normal distribution, as the majority of the values are distributed near zero. Thus, the dasymetric method preserves strong validity compared to the GND population distribution.

Figure 6 shows the spatial representation of error distribution. It clearly represents the areas that incorporate complex land use actions that impact the over estimation of the population (i.e. Industrial areas and highly urbanized areas show population spillovers due to job opportunities and economic potentials but, considering the land use types those areas are not suitable for living). Similarly, several rural areas make an impact on the underestimation of the population distribution.

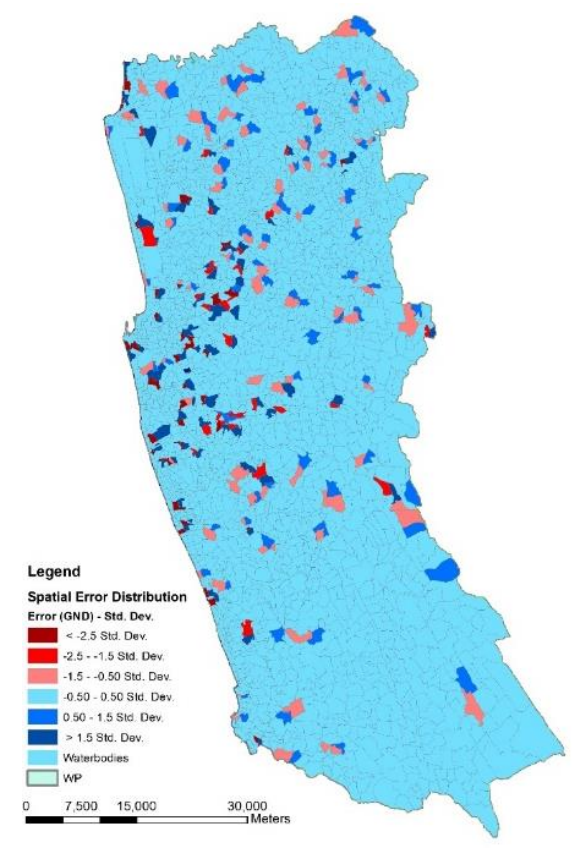

Figure 6: Error Distribution as GN Division Representation

Next, the study derived the flood inundation areas of the selected flooding events. As mentioned above, the flood data were collected as Image files (JPEG) and in order to estimate the population exposure, it is required to transfer the JPEG flood areas in to a spatial format. Therefore, the study utilized the Supervised Image Classification Techniques under the ArcGIS environment and has 
derived the flood layers under the vector format. Figure 7 shows the flood inundation areas in each selected year.

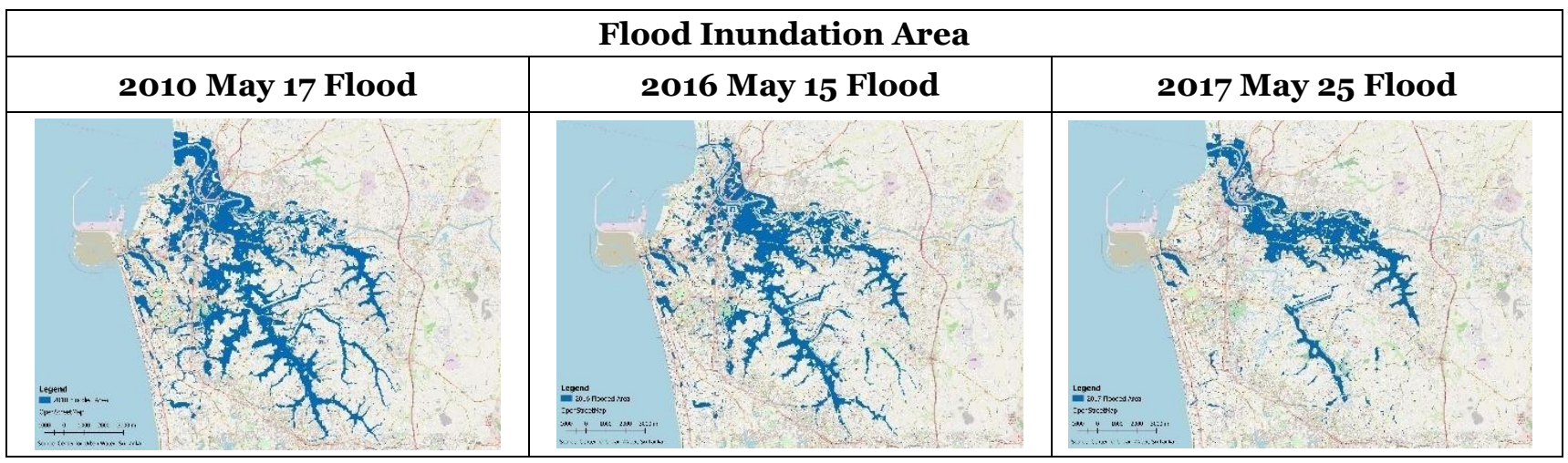

Figure 7: Selected Flood Events and Their Inundation Areas

In order to estimate population exposure, the study utilized the Overlaying Method of flood layers on the dasymetric map and calculates the affected population of each flooding event. This is the entry level vulnerability assessment method, but can be easily developed to resilience assessment, by adding vulnerable buffer zones and random and localized attacks to the residential layer (Julliard, et al., 2015), (Jang, et al., 2020). However, this study was limited to flood layers in order to assess the population resilience.

\section{Findings and discussion}

Table 3 presents population resilience under the GND and Dasymetric population distribution methods.

Table 3: Exposed Population as per the GND method and Dasymetric Methods.

\begin{tabular}{|l|c|c|c|}
\hline \multicolumn{4}{|c|}{ Estimated Population Exposure } \\
\hline Flood Event & GND Estimation (G) & Dasymetric Estimation (D) & Over Estimation (G-D) \\
\hline Year 2010 & $3,562,802$ & 334,826 & $3,227,976(90.6 \%)$ \\
\hline Year 2016 & $2,876,804$ & 251,007 & $2,625,797(91.2 \%)$ \\
\hline Year 2017 & $2,076,872$ & 134,135 & $1,942,738(93.5 \%)$ \\
\hline
\end{tabular}

Results clearly revealed that the GND population-based estimation overestimates the population exposure by more than $90 \%$ in each flood event. Meanwhile, the dasymetric estimation method precisely captures the impacted population cells and estimates the population exposure. Therefore, the proposed method is more suitable in downscaling the population estimation of urban flooding exposure, as it only evaluates the actual impact of the incident. Also, the proposed method is equally applicable for applying in community resilience assessment to any natural or manmade incident, as it can precisely distinguish the direct impact to the residential population. It is important to note that, the proposed dasymetric map demonstration is only applicable for static (residential) population exposure estimation and does not encounter the indirect and dynamic (moving) nature of population.

\section{Conclusion}

The study proposed dasymetric mapping techniques to estimate population exposure, as the existing methods have overestimated the population resilience. The proposed method presents strong accuracy of population downscaling according to the ancillary information and is capable of 
indicating the residential population resilience as a pixel representation. Therefore, the proposed method would be more applicable for the micro scale population resilience assessment.

However, the accuracy of the estimation highly depends on the dasymetric population map and resolution of the raster calculation. Hence, the detailed and precise land use feature layer affects the accurate population exposure assessment. It is also important to note that the proposed method is only applicable to the stock population resilience assessment as it is unable to incorporate the dynamic nature of population.

Furthermore, the proposed method can be easily improved to assess population exposure to other disasters due to the higher flexibility of the method. It is also applicable to the population risk forecast when adding vulnerable buffer zones, to measure the anticipated population exposure against random and localized attacks.

Therefore, the proposed procedure would be highly efficient and the method is precise, for community resilience assessment of urban flooding and other disaster driven scenarios, as it has the potentiality to capture the micro scale population disruptions.

\section{References}

Abenayake, C. C., Mikami, Y., Matsuda, Y. \& Jayasinghe, A., 2018. Ecosystem services-based composite indicator for assessing community resilience to floods. Environmental development, Volume 27, pp. 34-46.

Abenayake, C. et al., 2016. Applicability of extra-local methods for assessing community resilience to disasters: A case of Sri Lanka. Journal of Environmental Assessment Policy and Management, 18(8), p. 1650010.

Bajat, B., Krunić, N., Samardžić-Petrović, M. \& Kilibarda, M., 2013. Dasymetric modelling of population dynamics in urban areas. Geodetski vestnik, 57(4), pp. $777-792$.

DMC, et al., 2017. Sri Lanka Rapid Post Disaster Needs Assessment Floods and Landslides, May 2017, s.l.: Ministry of Disaster Management \& Ministry of National Policy and Economic Affairs in collaboration with the United Nations, World Bank and European Union..

Dover, J., 2015. Green infrastructure: incorporating plants and enhancing biodiversity in buildings and urban environments.. s.l.:s.n.

Hammond, M. J. et al., 2015. Urban flood impact assessment: A state-of-the-art review. Urban Water Journal, 12(1), pp. 14-29.

Holling, C. S., 1973. Resilience and stability of ecological systems. Annual review of ecology and systematics, 4(1), pp. 1-23.

Holloway, S., Schumacher, J. \& Redmond, R., 1997. People \& Place: Dasymetric Mapping Using Arc/Info.

Cartographic Design Using ArcView and Arc/Info, Missoula.

Jang, G. U., Joo , J. C. \& Park, J., 2020. Capturing the Signature of Topological Evolution from the Snapshots of Road Networks. Complexity.

Jayasinghe, A. B. \& Munasinghe, J., 2012. A Study of the Urbanizing Pattern in Kegalle District, Sri Lanka with Connectivity Analysis. International Journal of Scientific Knowledge , pp. 7-19.

Jayasinghe, A. B., Sathsarana, H. W. A. S., Rathnayake, R. \& Bandara, N. S., 2020. A Novel Method to Model Spatial Distribution of Population. International Journal of Innovative Technology and Exploring Engineering (IJITEE), $9(3 \mathrm{~S})$.

Jayasinghe, A., Sano, K., Abenayake, C. C. \& Mahanama, P. K. S., 2019. A novel approach to model traffic on road segments of large-scale urban road networks. MethodsX, Volume 6, pp. 1147-1163.

Jha, Abhas , K., Bloch, R. \& Lamond , J., 2012. Cities and flooding: a guide to integrated urban flood risk management for the 21st century., s.l.: The World Bank..

Julliard, R., Yun, . J. \& Rado, R., 2015. Robustness of Transportation Networks: The Case of Madagascar's Road Network. International Journal of Advancements in Research \& Technology, 4(5).

KALPANA, L. D. C. H. N., JAYASINGHE, A. \& ABENAYAKE, C., 2019. Accessibility Assessment of Cities Based on Network Analysis and Centrality.. Journal of the Eastern Asia Society for Transportation Studies, Volume 13, pp. 10621096.

Mennis, J., 2003. Generating surface models of population using dasymetric mapping. Professional Geographer, Volume 55, pp. 31-42.

Mileua, N. \& Queirósa , M., 2018. Development of a QGIS Plugin to Dasymetric Mapping. Portugal, s.n.

Nicolau, R., David, J., Catano, M. \& Pereira, J., 2019. Ratio of Land Consumtion Rate to Population Growth Rate Analysing of Diffrent Formulations Applied to Maniland Portugal. International Journal of Geo-Information.

Papagiannaki, K., Kotroni, V., Lagouvardos, K. \& Bezes, A., 2017. Flash Flood Risk and Vulnerability Analysis in

Urban Areas: The Case of October 22, 2015, in Attica, Greece. Perspectives on Atmospheric Sciences, pp. 217-223.

Pregnolato, M. et al., 2016. Assessing urban strategies for reducing the impacts of extreme weather on infrastructure networks.. Royal Society open science, p. p.160023.

Serre, D., 2018. DS3 model testing: assessing critical infrastructure network flood resilience at the neighbourhood scale. In: In Urban Disaster Resilience and Security. Cham: Springer, pp. 207 - 220.

Singh, P., Sinha, . V., Vijhani, . A. \& Pahuja, N., 2018. Vulnerability assessment of urban road network from urban flood.. International journal of disaster risk reduction, pp. 237-250. 
UN-Habitat, 2017. Trends in Urban Resilience 2017, s.l.: United Nations Human Settlements Programme (UNHabitat).

UNOCHA, 2016. Sri Lanka: Floods and landslides -Situation Report No. 2 (as of 26 May 2016), s.l.: United Nations Office for the Coordination of Humanitarian Affairs (OCHA).

Wahlstrom, M. \& Guha-Sapir, D., 2015. The human cost of weather-related disasters 1995-2015, Switzerland, Geneva: UNISDR.

Wenjuan, S., Paolo, B. \& Brian, D. D., 2020. Resilience metrics and measurement methods for transportation infrastructure: The state of the art. Sustainable and Resilient Infrastructure, 5(3), pp. 168-199.

WMO, 2015. Building Climate Resilience through Disaster Risk Reduction. [Online]

Available at: https://public.wmo.int/en/resources/bulletin/building-climate-resilience-through-disaster-risk-reduction$\underline{\mathbf{0}}$

WU, S., QIU, X. \& WANG, L., 2005. Population estimation methods in GIS and remote sensing: a review. GIScience \& Remote Sensing, Volume 42, pp. 80-96.

Yin, J. et al., 2016. Evaluating the impact and risk of pluvial flash flood on intra-urban road network: A case study in the city center of Shanghai, China. Journal of hydrology, pp. 138-145. 